\title{
Novel Superabsorbent Hydrogel Based on Natural Hybrid Backbone: Optimized Synthesis and its Swelling Behavior
}

\author{
Ali Pourjavadi,- Rouhollah Soleyman, Ghasem Rezanejade Bardajee, ${ }^{\dagger}$ and Somayeh Ghavami ${ }^{*}$ \\ Polvmer Research Laboratory, Deparment of Chemistry. Sharif Cniversitv of Technologv. \\ P. O. Box 11365-9516, Tehran, Iran. ${ }^{\times}$E-mail: purjatadasharif.edu \\ ${ }^{\dagger}$ Department of Chemistrv, Pavame Noor University Qazin Branch. P. O. Box 878, Qazvin. Iran \\ Received Hav 7, 2009, Accepted September 25, 2009
}

\begin{abstract}
The syinthesis of a novel superabsorbent hydrogel with natural hybrid backbone via graft copolymerization of acrylamide (AAm) onto kappa-carrageenan ( $\mathrm{kC}$, as a poly saccharide) and gelatin (as a protein) under classic thermal conditions is described. The Taguchi method as a strong experimental design tool was used for synthesis optimization. A series of hydrogels were synthesized by proposed conditions of Qualitek-4 Software. Considering the results of 9 trials according to analy sis of variance (ANOVA), optimum conditions were proposed. The swelling behavior of optimum hydrogel was measured in various solutions with $\mathrm{pH}$ values ranging from $\mathrm{l}$ to 13 . In addition, swelling kinetics, swelling in various organic solvents, various salt solutions and On-Off switching behavior were investigated. The hydrogel formation was confirmed by Fourier transform infrared spectroscopy (FTIR) and themogravinetrical analy sis (TGA). Surface morphology of the synthesized hydrogels was assessed by seaning electron microscope (SEM).
\end{abstract}

Key Words: Superabsorbent hỵdrogel. Natural hybrid backbone. Swelling behavior. Taguchi method

\section{Introduction}

Hydrogels are polymeric networks, which absorb and retain large amounts of water. ${ }^{\text {. The }}$ use of hýdrogels as biomaterials has recently gained great importance in view of the low toxicity and high biocompatibility presented by many of them. ${ }^{z, 3}$ The main hydrogel application areas today include: ${ }^{4}$ (i) topical applications as wound dressings. (ii) drug delivery systems. (iii) transdermal systems. (iv) dental applications. (v) injectable polymers. (vi) implants, (vii) ophthalmic applications, and (viii) stimuli-responsive sy stems.

Recently, natural materials (such as polysaccharides and proteins) have been used as the superabsorbent hydrogels backbone because of their exceptional properties. i.e.. biocompatibility, biodegradability, renewability. and nontoxicity. ${ }^{5.8}$

Carrageenans are commercially important hydrophilic poly saccharides that occur in numerous species of seaweeds. ${ }^{9}$ These linear sulfated polymers are composed of d-galactose and 3.6-anhyydrogalactose units. The types of carrageenans differ only in the position and number of ester sulfate groups.

Gelatin is a natural polymer. derived from collagen and due to its biodegradability ${ }^{j 1.51}$ and biocompatibility in physiological environments ${ }^{121 ?}$ is commonly used for pharmaceutical and medical applications.

The Taguchi method is a powerful experimental design tool developed by $\mathrm{G}$. Taguchi. It provides a simple. efficient. and systematic approach to optimize the designs for performance. quality and cost. The parameter design is the key step in the Taguchi method to achieve high quality without increasing cost and the same is adopted in this paper. The evaluation of results has been standardized by this method. which can easily be applied by researchers. ${ }^{1+1 \%}$

The present article represents an optimized synthesis (by Taguchi method) of a novel biopolymer-based superabsor- bent hydrogel via crosslinking graft poly merization of acrylamide (AAm) onto kappa-carrageenan/gelatin hỵbrid backbone. under thernal classic conditions.

\section{Experimental Section}

Matelials. Kappa-carrageenan $(\mathrm{kC}$. from Condinson $\mathrm{Co}$. Denmark). gelatin (from Darmstadt. Germany. Merck). N.N"* methylenebisacrylamide (MBA, from Merck), ammonium persulfate (APS. from Merck) and acrylanide (AAm. from Merck) were used as received. All other chemicals were also analytical grade. Double distilled water was used for hydrogel preparation and swelling measurements.

Instnumental Analysis. FTIR spectra ( $\mathrm{KBr}$ pellets) were recorded on $\mathrm{ABB}$ Bomem $\mathrm{MB}-100$ FTIR spectrophotoneter. Thermogravimetric analỵsis (TGA) was performed using polymer laboratories systems at a heating rate of $20^{\circ} \mathrm{C} / \mathrm{min}$ under nitrogen atmosphere. The morphology of the dried samples was examined using a scanning electron microscope. SEM, (Plilips, XL30) operated at $15.20 \mathrm{kV}$ after coating the samples with gold film.

Experimental Design. Selection of Factors and TheirLevels: The important factors in the synthesis of superabsorbent hydrogel including $\mathrm{kC} /$ gelatin weight ratio, AAm, MBA and APS amounts were selected as main factors. As well. three levels for each factor were chosen as shown in Tables 1 and 2.

Selection of Orthogonal Array and Assignment of Factors: Standard tables known as orthogonal arrays $(\mathrm{OA})$ are used for the design of the experiments in the Taguchi method. An OA with a 3 level and + factors are shown in Table 1 . This $O A$ is particularly designed with the symbol of L9. Each row in the array represents a trial condition with the factor levels. which are indicated by the numbers in the row. The columns correspond to the factors specified in this study and each columm 
contains three levels. Conditions (a total of 9 conditions) for the factors were assigned in Table 1. Software package Qualitek-4 version 6.3 was used for selection of orthogonal. optimum conditions and contribution of each factor.

Superabsortent Hydrogel Preparation. In general certain amount of $\mathrm{kC}(0.5-1.0 \mathrm{~g}$. according to Table 3$)$ and gelatin $(0.5-1.0 \mathrm{~g}$. according to Table 3$)$, were added to $30 \mathrm{~mL} \mathrm{H}_{2} \mathrm{O}$ at a three-neck reactor equipped with a mechanical stirrer while stirring $(200 \mathrm{rpm})$. The reactor was immersed in a thermostated water bath preset at $80^{\circ} \mathrm{C}$. After homogenizing the mixture, AAm (3.0-6.0 g, according to Table 3) was added to the reaction mixture and stirred for further 20 minutes. Then, MBA (0.03-0.09g, according to Table 3$)$ in $5.0 \mathrm{~mL} \mathrm{H} \mathrm{H}_{2} \mathrm{O}$ and finally. certain amount of APS $(0.03-0.09 \mathrm{~g}$. according to Table 3) in $5.0 \mathrm{~mL} \mathrm{H}_{2} \mathrm{O}$ were added. respectively. After $30 \mathrm{~min}$, the gel like material was separated and immersed in ethanol $(200 \mathrm{~mL})$ for $2+\mathrm{h}$. The completely hardened gel particles were filtered, washed with fresh ethanol $(2 \times 50 \mathrm{~mL})$ and dried in an oven at $50^{\circ} \mathrm{C}$ for $10 \mathrm{~h}$

Table 1. Experinental layouts of an L9 orthogonal array according to Taguchi s suggestion (the numbers in each column indicate the levels for the specific factors)

\begin{tabular}{ccccc}
\hline Trial & A & B & C & D \\
\hline 1 & 1 & 1 & 1 & 1 \\
2 & 1 & 2 & 2 & 2 \\
3 & 1 & 3 & 3 & 3 \\
4 & 2 & 1 & 2 & 3 \\
5 & 2 & 2 & 3 & 1 \\
6 & 2 & 3 & 1 & 2 \\
7 & 3 & 1 & 3 & 2 \\
8 & 3 & 2 & 1 & 3 \\
9 & 3 & 3 & 2 & 1 \\
\hline
\end{tabular}

Table 2. Experimental control factors and their levels

\begin{tabular}{lccc}
\hline Control factor & Level l & Level 2 & Level 3 \\
\hline $\mathrm{kC} / \mathrm{gelatin}(\mathrm{g} / \mathrm{g})$ & $0.5 / 1.0$ & $0.75 / 0.75$ & $1.0 / 0.5$ \\
AAm $(\mathrm{g})$ & 3.0 & 4.5 & 6.0 \\
$\mathrm{MBA}(\mathrm{g})$ & 0.03 & 0.06 & 0.09 \\
$\mathrm{APS}(\mathrm{g})$ & 0.03 & 0.06 & 0.09 \\
\hline
\end{tabular}

Table 3. A three-level orthogonal array (L9)

\begin{tabular}{ccccc}
\hline Trial & kC/gelatin $(\mathrm{g} / \mathrm{g})$ & AAm $(\mathrm{g})$ & MBA $(\mathrm{g})$ & APS $(\mathrm{g})$ \\
\hline 1 & $0.5 / 1.0$ & 3.0 & 0.03 & 0.03 \\
2 & $0.5 / 1.0$ & 4.5 & 0.06 & 0.06 \\
3 & $0.5 / 1.0$ & 6.0 & 0.09 & 0.09 \\
4 & $0.75 / 0.75$ & 3.0 & 0.06 & 0.09 \\
5 & $0.75 / 0.75$ & 4.5 & 0.09 & 0.03 \\
6 & $0.75 / 0.75$ & 6.0 & 0.03 & 0.06 \\
7 & $1.0 / 0.5$ & 3.0 & 0.09 & 0.06 \\
8 & $1.0 / 0.5$ & 4.5 & 0.03 & 0.09 \\
9 & $1.0 / 0.5$ & 6.0 & 0.06 & 0.03 \\
\hline
\end{tabular}

Water Absorbency Measurement. The degree of swelling was determined by gravimetric method. The tea bag (i.e. a 100 mesh nylon screen) containing the powdered sample $(0.1 \pm$ $0.01 \mathrm{~g})$ with average particle sizes between $40-60$ mesh $(250$ $400 \mu \mathrm{m})$ was immersed entirely in distilled water $(400 \mathrm{~mL})$ and allowed to soak for 30 min at room temperature. The equilibrium swelling (ES) capacity was measured twice at room temperature using the following formula:

$$
E S(g / g)=\frac{H_{2}-W_{1}}{W_{1}}
$$

where $W_{1}$ and $W_{2}$ are the weights of dry and swollen gel. respectively

Swelling Kinetics. To investigate the rate of absorbency of the hydrogel, certain anount of the sample $(0.1 \pm 0.01 \mathrm{~g})$ with average particle sizes between $40-60$ meshes $(250-400 \mu \mathrm{m})$ was poured into a weighed tea bag and immersed in $400 \mathrm{~mL}$ distilled water. At consecutive time intervals. the water absorbency of the hydrogel was measured according to the earlier mentioned method

The Environmental Sensitivity. pH Sensitivity: The procedures for these experiments are the same as section $2.5 . \mathrm{pH}$ dependency of swelling was measured by interaction of certain amounts of the hydrogel samples $(0.5 \pm 0.0 \mathrm{l}$ g) in solutions $(500 \mathrm{~mL})$ with different $\mathrm{pH}$. The various solutions were adjusted to the desired $\mathrm{pH}$ value by addition of diluted $\mathrm{HCl}$ or $\mathrm{NaOH}$. The On-Off switching by $\mathrm{pH}$ was carried out at buffered solutions with $\mathrm{pH} 1.6$ and $\mathrm{pH} 7.4$ with 0.01 molar concentrations.

Salinity: Swelling capacity of the lydrogel was measured in various salt solutions with different concentrations according to section 2.5 .

Solvent-induced Phase Transition: The procedures for these experiments are also the same as section 2.5 except that instead of distilled water, nixture of solvents was used. The On-Off switching by mixture of solvents was carried out at acetone/ water: $20 \%$ (swelling) and acetone/water: $60 \%$ (deswelling).

\section{Results and Discussion}

Synthesis and Mechanism Aspects. Crosslinking and graft copolymerization of PAAm onto backbones of $\mathrm{kC}$ and gelatin hybrid substrates were carried out in an aqueous medium using APS as a radical initiator and MBA as a crosslinking agent. The persulfate decomposes on heating (at $80^{\circ} \mathrm{C}$ ) and produces sulfate anion-radicals that abstract hydrogen atoms from the $\mathrm{OH}$ groups of $\mathrm{kC}$ or $\mathrm{NH}_{2}$ groups of gelatin backbones. This redox system results in active centers capable of initiating the radical poly merization of AAm, leading to a graft copolymer. Since a crosslinking agent (MBA) is present in the system. the copolymer contains a crosslinked structure (Figure 1).

Spectral Characterization. The grafting was confirmed by comparing the FTR spectra of polysaccharide and protein backbones before and after graft polymerization. Figure 2 shows the FTIR spectra of gelatin polyacrylamide. $\mathrm{kC}$ and sy nthesized hydrogel. respectively. In the spectrum of gelatin (Figure 2a), the broad band at $3430 \mathrm{~cm}^{-1}$ is due to stretching 

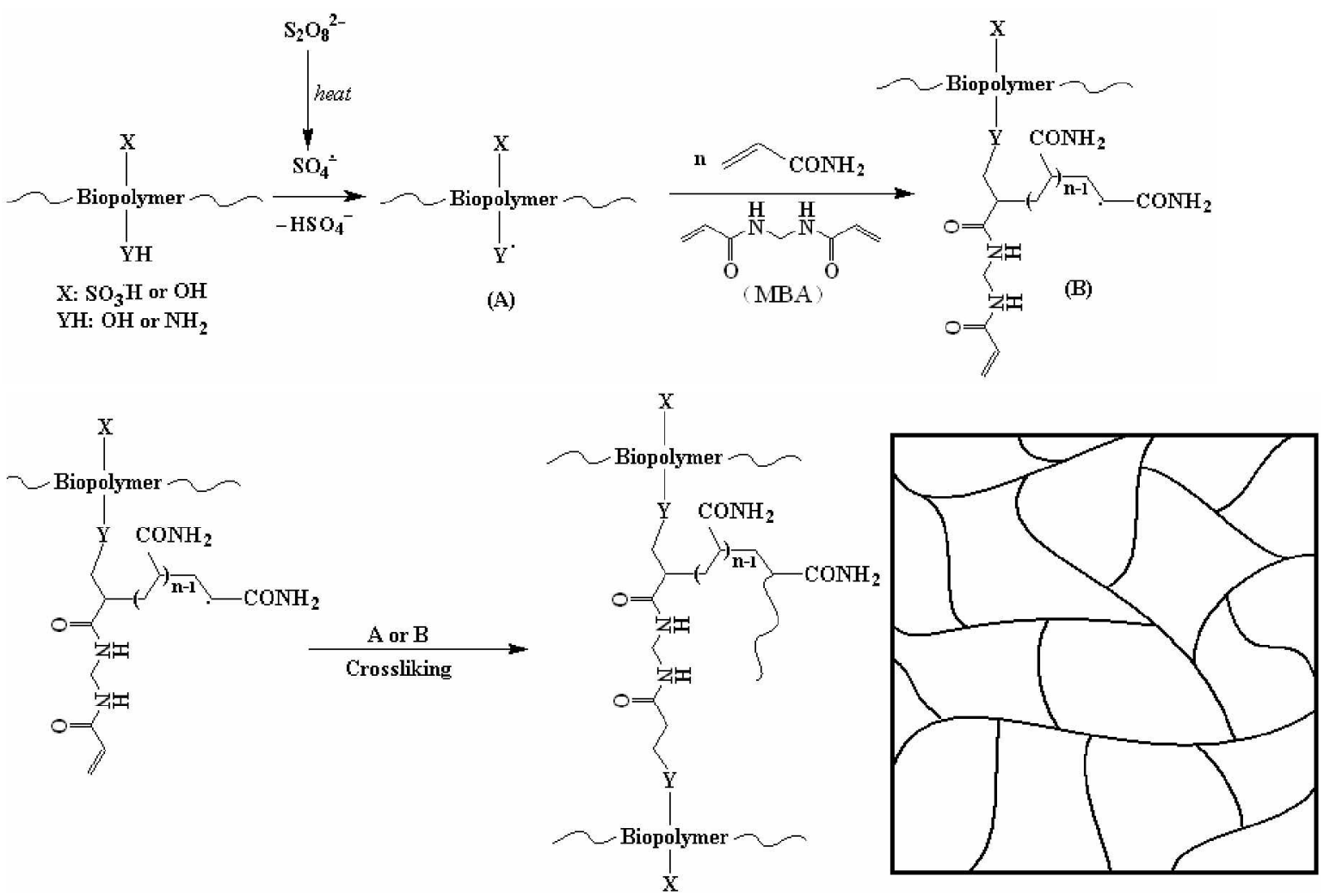

Figure 1. Proposed mechanism pathway for synthesis of the (kC/gelatin)-g-PAAm superabsorbent hydrogel.

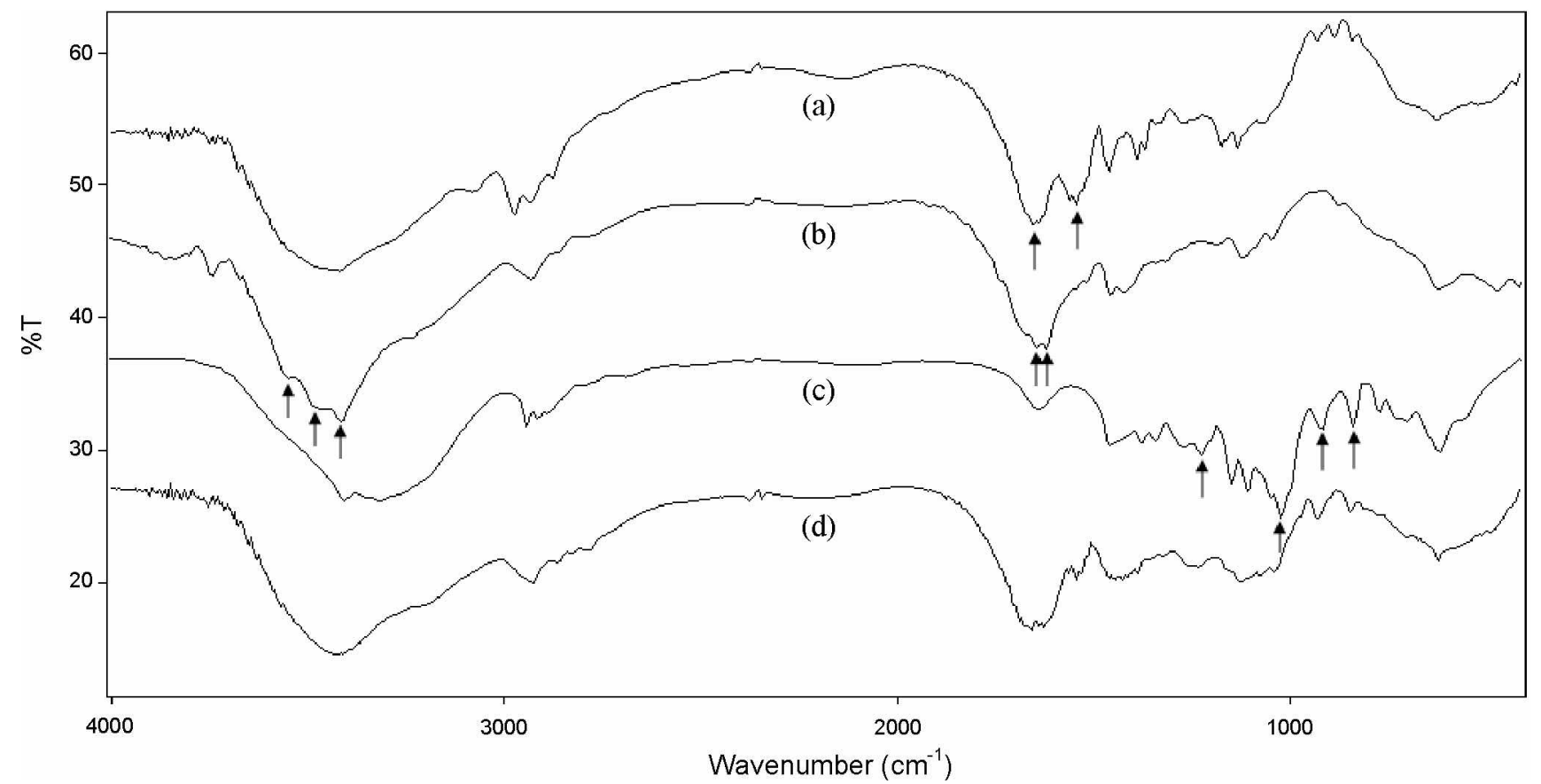

Figure 2. FTIR spectra of (a) gelatin, (b) PAAm, (c) $\mathrm{kC}$ and (d) (kC/gelatin -g-PAAm superabsorbent hydrogel synthesized under optimized conditions, respectively.

vibration modes of amino groups. Two bands at 1545 and $1650 \mathrm{~cm}^{.1}$. can be attributed to $\mathrm{N}-\mathrm{H}$ bending vibration and amide group. respectively. The bands observed at 840,917 . 1022 and $1227 \mathrm{~cm}^{-1}$ can be attributed to D-galactose-4-sulfate.
3.6-anlydro-D-galactose, glycosidic linkage and ester sulfate stretching of $\mathrm{kC}$, respectively (Figure $2 \mathrm{c}$ ). All indicated peaks in prior spectra were objectively repeated in the spectrum of final hydrogel (Figure 2d). 
TGA traces of (a) superabsorbent hydrogel and (b) plyy sical mixture of $\mathrm{kC} /$ gelatin/PAAm are presented in Figure 3. This Figure and the data summarized in Table 4, shows the improvement of the thermal stability of superabsorbent hydrogel. According to Table 4, the related values of the superabsorbent hydrogel such as $\mathrm{T}_{10}\left(282.8^{\circ} \mathrm{C}\right)$ and char yield at $550^{\circ} \mathrm{C}$ $(37.5 \%)$ are higher compared to that of the physical mixture of $\mathrm{kC} /$ gelatin/PAAm $\left(\mathrm{T}_{11}=247.1^{\circ} \mathrm{C} . \mathrm{Y}=30.1 \%\right.$ ). As one can see. this sample is found to be the most thermally stable one studied. The ionic and crosslinked stnicture in the network may act as heat bamers and as a consequence enhance the overall thermal stability of the superabsorbent hy'drogel.

Optimization of Water Absonbency. According to previous works. ${ }^{1 ; \cdots 1]}$ the factors and corresponding levels affecting the ultimate swelling capacity of the entitled hydrogel were selected

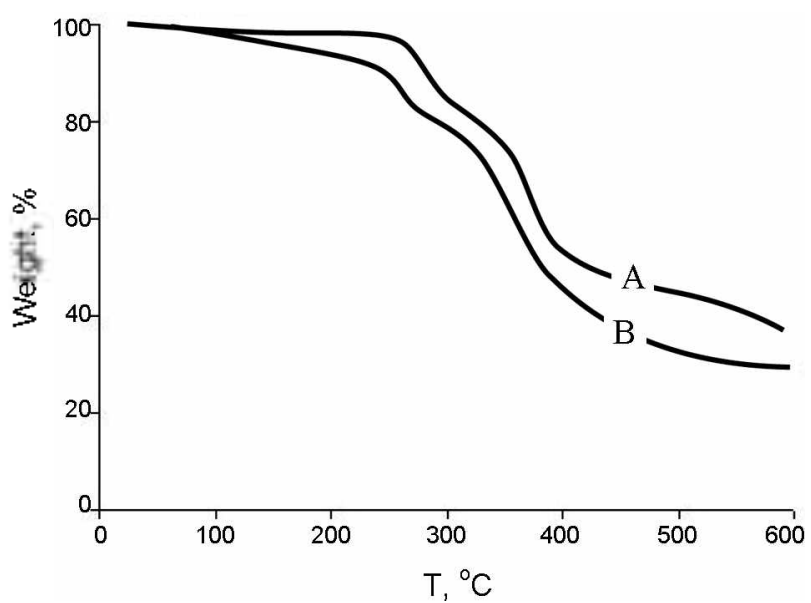

Figure 3. TGA of (a) superabsorbent hydrogel and (b) physical mixture of $\mathrm{kC} / g$ elatin/PAAm.

Table 4. Thermal properties of the optimized (kC/gelatin)-g-PAAm and physical mixture of $\mathrm{kC} / \mathrm{gelatin} / \mathrm{PAAm}$

\begin{tabular}{ccccc}
\hline \multirow{2}{*}{ Polymer } & \multicolumn{2}{c}{ Temperature ("C) at weight loss $^{\circ}$} & \multirow{2}{*}{$\mathrm{Y}^{a}$} \\
\cline { 2 - 4 } & $10 \%$ & $30 \%$ & $50 \%$ & $(\mathrm{wt} \%)$ \\
\hline $\mathrm{A}$ & 282.8 & 364.1 & 419.0 & 37.5 \\
$\mathrm{~B}$ & 247.1 & 337.2 & 385.1 & 30.1 \\
\hline
\end{tabular}

${ }^{\circ} \mathrm{Char}$ yield $550^{\circ} \mathrm{C}$ in nitrogen.

Table 5. Experimental results for swelling of superabsorbents for 9 trials

\begin{tabular}{cccccccccc}
\hline Trial & 1 & 2 & 3 & 4 & 5 & 6 & 7 & 8 & 9 \\
\hline ES $(g / g)$ & 70 & 32 & 10 & 30 & 68 & 90 & 48 & 74 & 50 \\
\hline
\end{tabular}

Table 6. Optinum conditions and pertormance

\begin{tabular}{ccc}
\hline Factor & Level description & Optimum conditions \\
\hline kC/gelatin $(g / g)$ & 2 & $0.75 / 0.75$ \\
AAm $(g)$ & 2 & 4.5 \\
MBA $(g)$ & 1 & 0.03 \\
APS $(g)$ & 1 & 0.03 \\
\hline
\end{tabular}

(Tables 1-2). After selection of factors and their levels. an orthogonal array appropriate for 4 factors with 3 levels for each factor (L9 OA) was applied (Tables 1 and 3). The results for the synthesis of 9 hydrogels with conditions proposed by Taguchi statistical method are given in Table 5 (each measurement was repeated two times). Finding the optinum conditions and contribution of each factor was found by using ANOVA. neglecting the interaction between factors. According to analysis performed by software Qualitek-4. optinum conditions are shown in Table 6.

Swelling Kinetics. Figure + represents the dynanic swelling behavior of the superabsorbent in water. The time required to reach the equilibnum swelling capacity was acheved after about $10 \mathrm{~min}$. The data may be well fitted with a Voigt-based equation. $^{\text {ig }}$

The rate parameter of our superabsorbent is $1.7 \mathrm{~min}$ for sizes between $250-400 \mu \mathrm{m}$.

The Environmental Sensitivity. pH Sensitivity: The swelling behavior of the superabsorbent hydrogel was studied at room temperature at various $\mathrm{pH}$ values between 1 and 13 (Figure 5a). ${ }^{2-}$ To prepare the $\mathrm{pH}$ media standard $\mathrm{HCl}(\mathrm{pH} \mathrm{1}$ ) and $\mathrm{NaOH}(\mathrm{pH}$ 13) solutions were diluted with distilled water to reach the desired acidic and basic $\mathrm{pHs}$, respectively. The swelling of the hydrogel increased with increasing $\mathrm{pH}$ from $\mathrm{I}$ to 5, but it is decreased in the $\mathrm{pH}$ range between 7 and 13. In the range between 5 and 7 , a minimum was observed. At $\mathrm{pH}=$ 5 . all the $-\mathrm{NH}_{2}$ groups of gelatin were comverted to $-\mathrm{NH}_{3}{ }^{-}$, and at $\mathrm{pH}=7$, all the $-\mathrm{SO}_{3} \mathrm{H}$ groups of $\mathrm{kC}$ were converted to $-\mathrm{SO}_{3}{ }_{3}$. Because of these conversions and ion-ion repulsions. two maximum were observed in this Figure. In acidic solution. ionic strength of the medium increases and the charges of the $-\mathrm{SO}_{3}{ }^{-}$anions are slielded by the counter ions so that prevent efficient repulsion. At the $\mathrm{pHs}$ greater than 7. the $\mathrm{Na}^{+}$cations from $\mathrm{NaOH}$ shield the $-\mathrm{SO}_{3}{ }^{-}$groups and prevent the perfect anion-anion repulsion. Also, the ionic strength of the medium is increased and consequently the swelling is decreased. The optimally prepared $\mathrm{pH}$-sensitive hydrogel, showed a reproducible On-Off switching behavior when the environmental $\mathrm{pH}$ of the sample was alternatively changed between 7.4 and

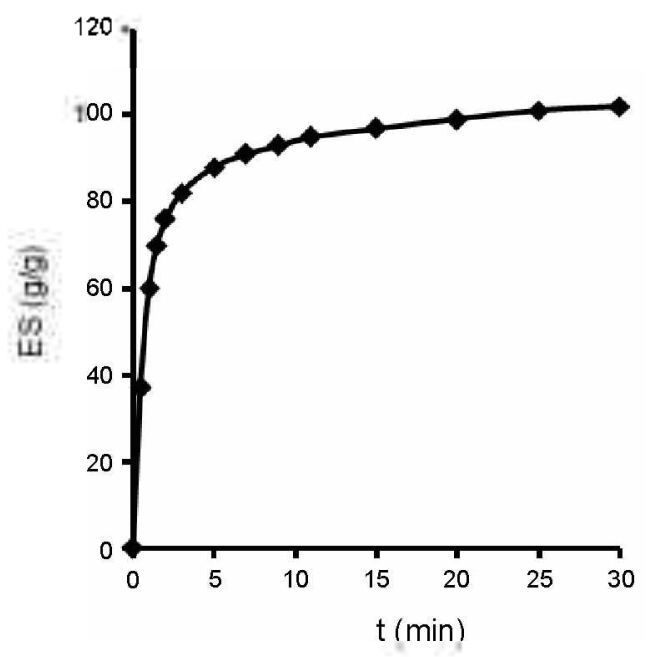

Figure 4 . The swelling kinetics of optimized sample in distilled water. 

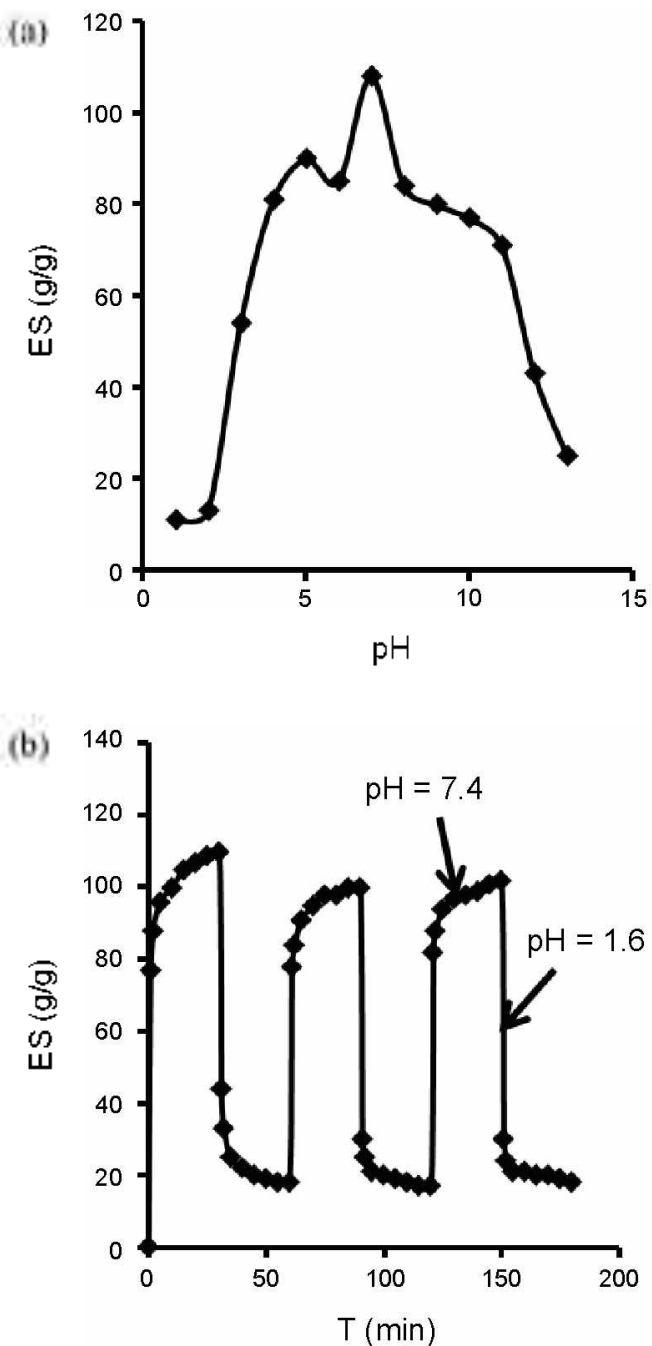

Figure 5. (a) Swelling dependency of ( $\mathrm{kC} /$ gelatin $)$-g-PAAm on $\mathrm{pH}$ and (b) On-Ott switching behavior of the optimized superabsorbent hydrogel in 0.01 molar buftered solutions with $\mathrm{pH}=7.4$ and $\mathrm{pH}=$ 1.6.

1.6 (Figure 5b). This responsiveness behavior may be of significant importance in controlled delivery of drugs to colon having alkaline medium

Salinity: In these experiments, the swelling capacity was measured in various salt solutions. It is obvious that swelling decrease is strongly depended on the "type" and "concentration" of salt added to the swelling medium. ${ }^{3-35}$ The effect of cation type (cations with different radius and charge) on swelling behavior is shown in Figure 6. With increasing the charge of cation. degree of crosslinking is increased and swelling is consequently decreased. Therefore, the absorbency for the hydrogel in the mentioned salt solutions is in the order of monovalent $>$ divalent cations. The effect of cation radius on swelling is shown in Figure 6. As reported by Pass et al.. ${ }^{76}$ the carboxỵlate anion interacts with small cations. e.g. $\mathrm{Li}^{-}$, stronger than with large cations, e.g. $\mathrm{Cs}^{-}$. The stronger interactions of carboxy late-small cation have been observed using measurement of activating coefficients of various cations in several salt solutions. As a result, the absorbency in monovalent and divalent cation salt solutions is in the order of $\mathrm{CsCl}>\mathrm{NaCl}>$

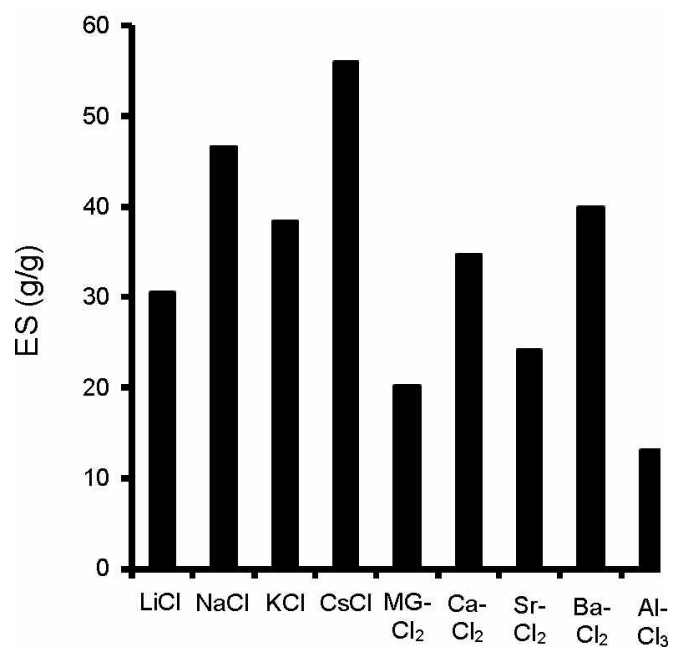

Figure 6. Swelling capacity of the superabsorbent hydrogel in difterent chloride salt solutions $(0.15 \mathrm{M})$.

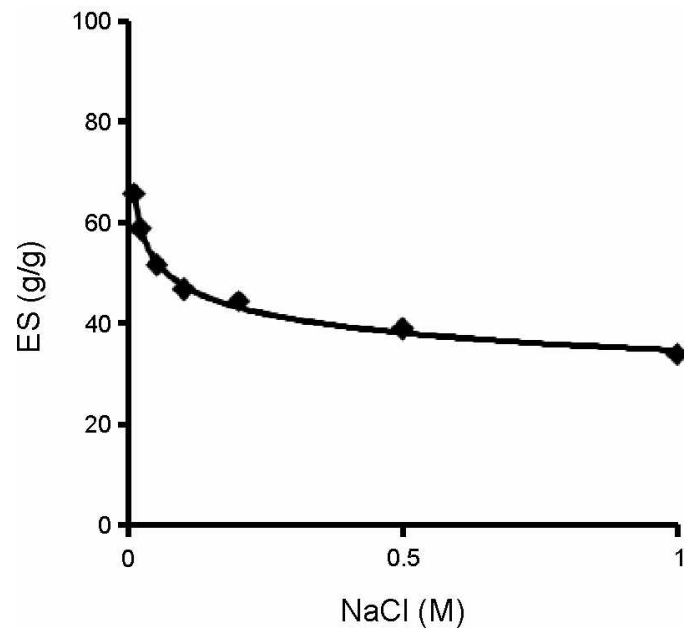

Figure 7. The swelling capacity variation of ( $\mathrm{kC} / g$ gelatin)-g-PAAm in various concentrations of $\mathrm{NaCl}$ solution.

$\mathrm{LiCl}$ and $\mathrm{Ba}^{2-}>\mathrm{Ca}^{2-}>\mathrm{Mg}^{2-}$, respectively. In this case. there is an exception on $\mathrm{K}^{-}$cation. This unexpected behavior could be rationalized to chelating property of $\mathrm{K}^{-}$cation with $\mathrm{kC}$. so a behavior similar to ionic crosslinking of divalent cations was observed. In fact. aqueous solutions of $\mathrm{kC}$ with specific cations, especially $\mathrm{K}^{+}$. form physically crosslinked thermoreversible polyelectrolyte gels. The stronger interaction between sulfate groups of $\mathrm{kC}$ molecules and large cations have also been observed by Pass et al. using measurement of activating coefficients of various cations in several salt solutions. Thus. $\mathrm{kC}$ has the highest affinity for crosslinking with $\mathrm{K}^{+}$anong monovalent cations of the studied salt solutions. As a result. swelling of the synthesized hydrogels in $\mathrm{KCl}$ solution is lower than in $\mathrm{LiCl}$ and in $\mathrm{NaCl}$ solutions. Similar results are also observed in the case of chloride solutions of $\mathrm{Mg}^{2+} \cdot \mathrm{Ca}^{2+} \cdot \mathrm{Sr}^{2-}$. and $\mathrm{Ba}^{2-}$ (Figure 6).

Figure 7 illustrates a reverse and power law relationship between concentration of $\mathrm{NaCl}$ solutions and swelling capacity of the hydrogel. Charge screening effect is the main explanations for the intense loss of swelling. The known relationship 
between swelling and concentration of salt solution is stated as following equation: ${ }^{2+}$

$$
\text { Swelling }=\mathrm{k}[\text { salt }]^{-n}
$$

where $\mathrm{k}$ and $\mathrm{n}$ are constant values for an individual superabsorbent. The $\mathrm{k}$ value is swelling at a high concentration of salt and $n$ value is a measure of salt sensitivity. Figure 7 indicates that increasing the concentrations of salt to higher than about $0.5 \mathrm{M}$ has no appreciable influence on absorbency of the superabsorbent. The $\mathrm{k}$ and $\mathrm{n}$ values for $\mathrm{NaCl}$ solutions are 34.7 and 0.137 . respectively

Solvent-induced Phase Transition: In the present study, the swelling changes of the optimized hydrogel were examined in various water-solvent systems (Figure 8a). The swelling-loss in these mixtures can be attributed to the change of the solubility parameter of the solvent-water mixture ${ }^{28-5}$ Anionic
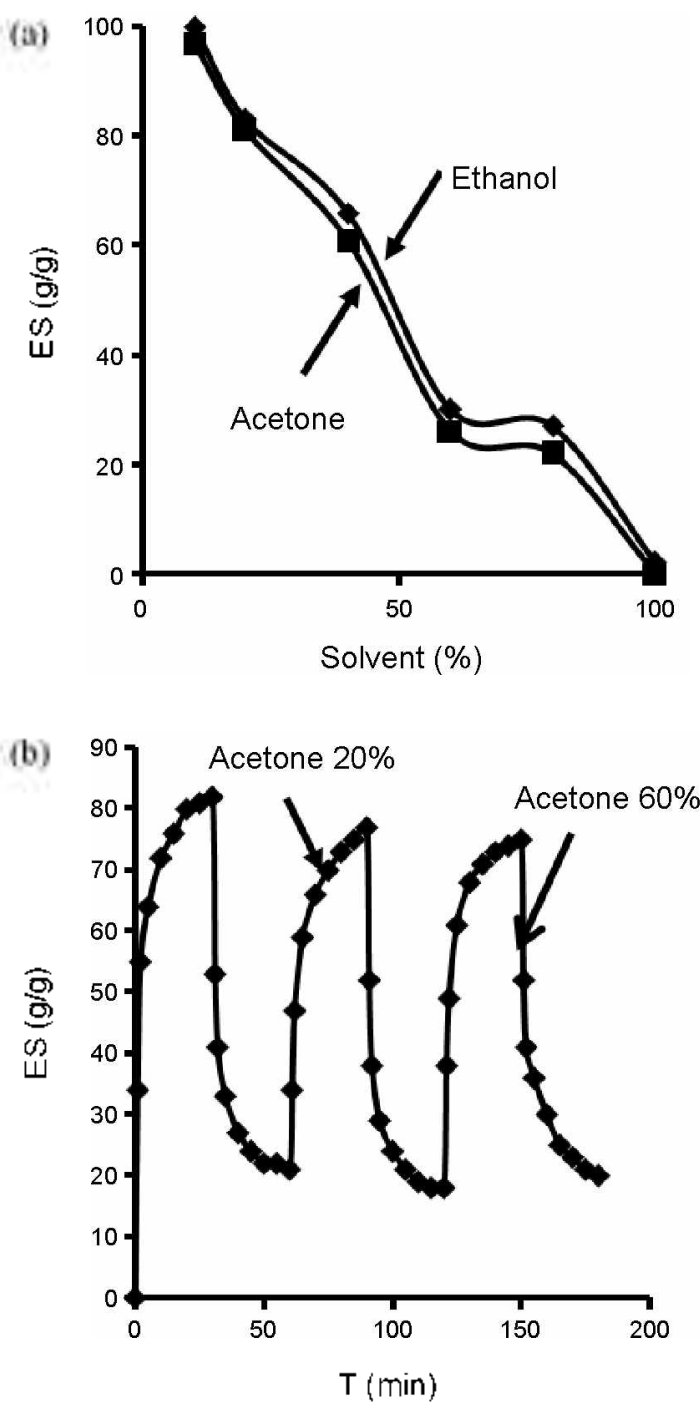

Figure 8. (a) Effect of organic solvents (ethanol, acetone) on the water absorbency of superabsorbent hydrogel and (b) On-Off switching behavior of the optimized superabsorbent hydrogel, in acetone/water: $20 \mathrm{wt} \%$ (swelling), acetone/water: $60 \mathrm{wt} \%$ (deswelling). groups are easily solvated by water molecules. but the organic solvent molecules (ethanol or acetone) can not solvate the anionic groups. As a consequence. the swelling capacities are considerably decreased

The optimally prepared environmental-sensitive superabsorbent composite. showed a reproducible On-Off switching behavior when the environmental mixture of the sample was altematively changed between acetone/water: $20 \mathrm{wt} \%$ and acetone/water: 60 wt $\%$. In literature, M. J. Zohuriaan-Mehr and $e t$ al. ${ }^{3 i}$ reported that optimum hỵdrogel of Gum Arabicacrylic swollen highly in a solvent-water mixture (solvent: ethanol, methanol. DMSO. ethylene glycol and glycerol). Our superabsorbent hydrogel, similar to mentioned lydrogel showed a reproducible swelling-deswelling behavior when the envirommental medium was changed altematively between the acetone-water mixtures $20 \mathrm{wt} \%$ and $60 \mathrm{wt} \%$ (Figure $8 \mathrm{~b}$ ). The collapse of the gel is a result of the total depletion of water

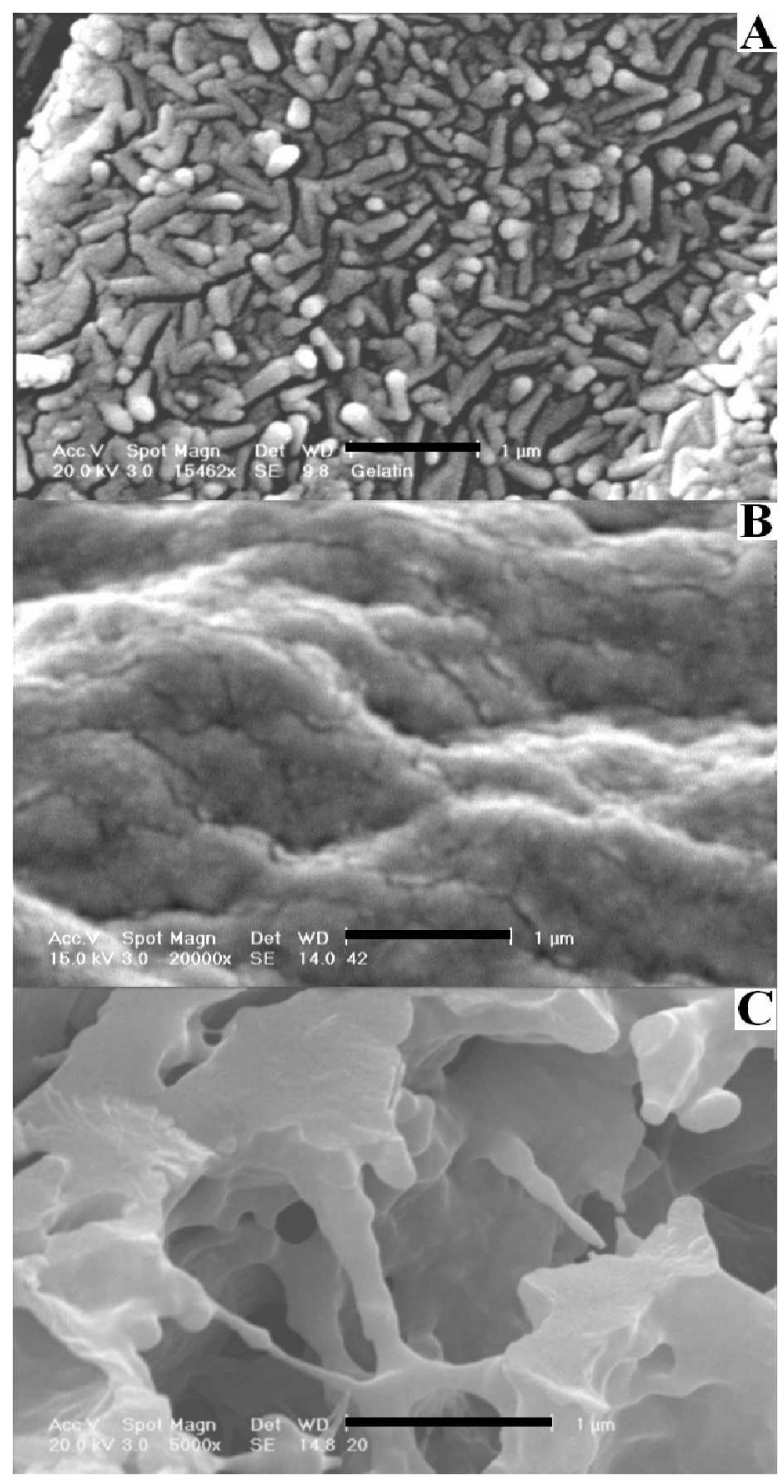

Figure 9. SEM photographs of (a) gelatin, (b) $\mathrm{kC}$ and (c) (kC/gelatin)g-PAAm superabsorbent hydrogel synthesized under optimized conditions. 
from the solvated polymer network. In higher percents of acetone. the capability of the hydrogen bonding formation between the molecules of the acetone-water and the hydrogel macromolecular network is decreased. The nonsolvent acetone dissociates the water-hydrogel hy'drogen bonding and as a result, the hydrogel is collapsed at a certain concentration of acetone-water. The contracted gel is reswollen when it is located in another acetone-water mixture with higher water content. $^{3(1}$

Surface Morphology of Hydrogels. Figure 9 shows the scanning electron microscopic (SEM) pictures of the (a) gelatin (b) $\mathrm{kC}$ and (c) synthesized hydrogel under optimum conditions. It is supposed that the pores are the regions of water permeation and interaction sites of external stimuli with the hydrophilic groups of the graft copolymers. These pictures verify that superabsorbent hydrogel has porous structure, but started materials (kC and gelatin) have no porosity in their structures.

\section{Conclusion}

In the present work, we prepared a novel superabsorbent hỵdrogel by crosslinking graft copolymerization of acry lamide onto polysaccharide/protein hybrid backbone. The optimum reaction conditions to obtain maximum water absorbency (103 g/g) were found to be: kC/gelatin: $1(0.75 / 0.75 \mathrm{~g} / \mathrm{g})$. AAm: $4.5 \mathrm{~g}$. MBA: $0.03 \mathrm{~g}$ and APS: $0.03 \mathrm{~g}$. Swelling measurement of the hydrogels in different salt solutions showed appreciable swelling capacity. especially in $\mathrm{CsCl}$ and $\mathrm{BaCl}_{2}$ solutions. Also the superabsorbent hydrogels exhibited high sensitivity to $\mathrm{pH}$. so that. several swelling changes of the hydrogel were observed in lieu of $\mathrm{pH}$ variations in a wide range $(1-13)$. Furthermore the reversible swelling-deswelling behavior in solutions with acidic and basic $\mathrm{pH}$ makes the hydrogels as a suitable candidate for controlled drug delivery systems. In addition it is expected that the resulted superabsorbent polymers show more compatibility with body when they are used as dnıg delivery sỵstems. because of polỵsaccharide/ protein as a natural lybrid backbone.

\section{References}

1. Hemnink, W. E.: van Nostrum, C. F. Adv. Dng Deliv. Rev. 2002 ,
$54,13$.

2. Lee, K. Y,; Mooney, D. T. Chem. Rev 2001, 101, 1869.

3. Hoftman, A. S. Adv. Ding Deliv. Rev 2002, 13, 3.

4. Nguyen, K. S.; West, J. L. Biomaterials 2002, 23, 4307.

5. Savoji, M. T.; Pourjavadi, A. Polym. Eng. Sci. 2006, $46,1778$.

6. Pourjavadi, A: Amini-Fazl, M. S.; Barzegar, S. J. Appl Pohm. Sci. 2008, 107, 2970.

7. Pourjavadi, A; Ghasemzadeh, H; Hosseinzadeh, H. e-Polvmers 2004, 27

8. Pourjavadi, A; Harzandi, A. M: Hosseinzadeh, H. Eur. Polv. $J$. 2004, 40,1363

9. Kirk, R. E:; Othmer, D. F. In Encyclopedia of Chemical Techologv, Kroschwitz, T. I. Howe-Grant, M., Eds.; Wiley: New York, U. S. A., 1992: Vol. 4, p 942.

10. Ikada, Y,; Tábata, Y. Adv' Dnig Deliv. Rev. 1998, 31, 287.

11. Yamamoto, M.; Ihada, Y.; Tabata, Y. J. Biontater Sci. Polm. Ed. 2001, 12, 77

12. Kuịjers, A. J.: Wachem, P. B. V.; Luyn, M. J. V.; Plantinga, J. A.; Engbers, G. H. J. Bionted. Water Res. 2000,51, 136 .

13. Yå, C. H.; Lin, B. S.: Hsu, S. H.: Chen, Y. S.: Tsai, C. C. J. Biomed Mater: Res. 2004, 69, 709.

14. Tohnson, R. A. In M fillerand Frethd's Probability and Statistics for Engineers; PHI, 2001.

15. Garcia-Diaz, A.; Philips, D. T. In Principles of Expenimental Design and Anatysis; Chapman \& Hall, 1995.

16. Douglas, C. M. In Design and Analvsis of Experiments; Wiley; New York, U. S. A., 2001

17. Pourjavadi, A.; Harzandi, A. M.: Hossenzadeh, H. En. Polym. J. $2004,40,1363$.

18. Pourjavadi, A.; Bardajee, G. R.; Solemman, R. J. Appl. Polm. Sci. 2009, 112, 2625.

19. Pourjavadi, A.; Soleyman, R.: Bardajee, G. R. Starch Stärle 2008, 60, 467 .

20. Bardajee, G. R.: Pourjavadi, A.: Soleyman, R.: Sheikh, N. Micl. Instr: and Weth. in Phys. Res. B 2008, 266, 3932.

21. Pourjavadi, A.; Amini-fazl, M. S. Polmer Int 2007, 56, 283.

22. Pourjavadi, A.; Harzandi, A. M.: Hosseinzadeh, H. Hacromolecular Research 2005, 13,403.

23. Omidian, H.; Hashemi, S. A.; Sammes, P. G.; Meldrum, I. Polvmer 1998, 39.6697.

24. Flory P. T. In Principles of Polmer Chentisty, Comell University Press: New York, Ithaca, 1953.

25. Pourjavadi, A.; Hosseinzadeh, H.; Mazidi, R. J. App. Poly Sci. 2005, 98, 255.

26. Pass, G.; Philips, G. O.: Wedlock, D. J. Macromolecules 1977, 10. 197 .

27. Tianqi, F.; Lixia, G. J. Polym. Hater, 2002, 19, 103.

28. Grulke, E. A. In Polmmer Handbooh. Brandrup, T. Immetgut, E. H. Grulke, E. A., Eds.; Wiley: New York, U. S. A. 1999: Vol. 2, p 675.

29. Zohuriaan-Mehr, M. I.; Motazedi, Z.; Kabiri, K.; ErshadLangroudi, A.; Allahdadi, I. J.Appl Polm Sci. 2006, 102, 5667. 